Personalidade Acadêmica Homenageada:

Augustus B. Cochran III (Agnes Scott College)

\title{
EXPORTAÇÃO DE BOVINOS PARA O ABATE, ORDEM ECONÔMICA E O DIREITO ANIMAL, ESTUDO DE CASO: PORTO DE SANTOS E O NAVIO MV NADA
}

\section{EXPORT OF CATTLE FOR SLAUGHTER, ECONOMIC ORDER AND ANIMAL LAW, CASE STUDY: PORTO DE SANTOS AND THE SHIP MV NADA}

MAXIMILIANO AUGUSTO VENÇÃO SÁ Mestrando em Direito Empresarial e Cidadania pelo Centro Universitário de Curitiba UNICURITIBA (2018), pós-graduado em Direito Aplicado pela Escola da Magistratura do Paraná - EMAP (2012), pós-graduando em Direito Processual Civil pelo Instituto de Direito Bacellar (2018), graduado em Direito pelo Centro Universitário de Curitiba UNICURITIBA (2011).

\section{CAROLINA PEDERZOLI}

Graduanda em Medicina Veterinária pela Universidade Positivo - UP (2017-), Pósgraduada em Controladoria pela Universidade Federal do Paraná - UFPR (2013), graduada em Ciências Contábeis pela Faculdade de Educação Superior do Paraná FESP (2011).

\section{RESUMO}

A pesquisa tem por objetivo, pautado no método dedutivo, analisar de que forma o ente Público pode intervir na ordem econômica, especialmente quanto à exportação de bovinos para o abate, examinando as decisões judiciais que trataram recentemente do assunto. $\mathrm{O}$ caso envolvendo o Porto de Santos e o embarque de 


\section{Personalidade Acadêmica Homenageada:}

Augustus B. Cochran III (Agnes Scott College)

cerca de 25 (vinte e cinco) mil cabeças de gado com destino à Turquia, gerou grande polêmica, suscitando discussões acerca dessa modalidade de exportação, quanto a ordem econômica brasileira e as relações internacionais com os países importadores trouxe à tona o debate dos direitos e bem-estar dos animais envolvidos e explorados economicamente. Em sede de ação civil pública, a situação complicou-se, uma vez que o juízo da 25 $5^{\text {a }}$ Vara Cível Federal de São Paulo, em liminar, impediu a saída do navio MV Nada, suspendeu as exportações de gado para o abate em todo território nacional, até que os países importadores firmassem acordo inter partes com a finalidade de que fossem adotadas as técnicas de abate em observância ao previsto no ordenamento jurídico brasileiro, ainda, determinou o desembarque dos bovinos e a remessa desses às fazendas de origem. A decisão provocou um cenário de tensão, de um lado buscava-se garantir o bem-estar dos animais embarcados, por outro lado a segurança econômica diante da possibilidade de descumprimento contratual, que afetaria a credibilidade do país no mercado mundial. Após recursos interpostos pela União Federal, o Tribunal Regional Federal da 3르 Região reformou a decisão liminar de primeiro grau, a princípio para determinar a partida imediata do navio, tendo em vista que, o desembarque dos bovinos e remessa às fazendas de origem demandaria grande logística a qual para ser executada demoraria até 30 (trinta) dias, o que submeteria os animais à condições ainda mais degradantes, pois nesse período de tempo, enquanto estivesse atracado no Porto de Santos, a limpeza do navio no qual estavam não poderia ser realizada devido ao risco de dano ambiental à costa brasileira. Posteriormente, a Presidência do referido órgão judicial, decidiu pela suspensão da liminar que impedia a exportação de gado para o abate em todo território nacional, até o trânsito em julgado da ação civil pública. No entanto, a discussão quanto à exportação de bovinos para o abate no exterior estaria longe de ter um desfecho. Em desdobramento da situação exposta, o Município de Santos, Estado de São Paulo, alterou seu Código de Posturas, por meio da Lei Complementar no 996/2018, que em suma passou a vedar o transporte de carga viva nas áreas urbanas e de expansão urbana do Município. A nova disposição, indiretamente, inviabilizou o escoamento através do Porto de Santos, da produção de gado para o abate no exterior, prejudicando os produtores rurais brasileiros que o utilizavam. Neste 
Personalidade Acadêmica Homenageada:

Augustus B. Cochran III (Agnes Scott College)

caso, o Supremo Tribunal Federal foi instado a dirimir o impasse em duas arguições de descumprimento de preceito fundamental de relatoria do Ministro Luiz Edson Fachin, as quais em bosquejo, asseveraram que a Lei Complementar o 996/2018 tratou de matéria cuja competência é privativa da União, assim como de sua consequência indireta de grave dano à ordem econômica brasileira. Liminarmente o Ministro-Relator suspendeu, em ambas ADPFs, a eficácia dos dispositivos controversos da Lei Complementar Municipal, em seguida tais decisões foram referendadas em Tribunal Pleno. Dessa forma, o contexto intrincado envolvendo assuntos delicados como religião e ordem econômica dispostos em nossa Carta Constitucional, mostram-se relevantes para debater o direito empresarial à luz da interpretação que tem-se dado pelas Cortes Superiores da transformação de paradigmas, progredindo para uma visão biocêntrica do Direito e reconhecimento dos seres senscientes, sua tutela e proteção.

PALAVRAS-CHAVE: Intervenção do Estado na Ordem Econômica; Exportação de Gado em Pé; Direito Animal.

\section{REFERÊNCIAS}

ABPA - Associação Brasileira de Proteina Animal. A Técnica de Abate Halal. Disponível em: <http://abpa-br.com.br/setores/avicultura/mercado-externo/a-tecnicade-abate-halal>. Acesso em: 11/11/2018.

BRASIL. Constituição (1988). Constituição da República Federativa do Brasil: promulgada em 5 de outubro de 1988. Planalto. Disponível em: < http://www.planalto.gov.br/ccivil_03/constituicao/constituicaocompilado.htm>. Acesso em: 11/11/2018.

Decreto no 24.548 de 3 jul. 1934. Aprova o Regulamento do Serviço de Defesa Sanitária Animal. Site Planalto. Disponível em: $<$ <ttp://www.planalto.gov.br/ccivil_03/decreto/1930-1949/d24548.htm>. Acesso em: 15/11/2018.

Decreto no 4.711 de 29 mai. 2003. Dispõe sobre a coordenação do Sistema
Nacional de Trânsito. Site Planalto. Disponível em: < 
Personalidade Acadêmica Homenageada:

Augustus B. Cochran III (Agnes Scott College)

http://www.planalto.gov.br/ccivil_03/decreto/2003/D4711.htm>.

Acesso

em: 15/11/2018.

. Decreto no 5.741 de $\mathbf{3 0}$ mar. 2006. Regulamenta os arts. 27-A, 28-A e 29A da Lei no 8.171, de 17 de janeiro de 1991, organiza o Sistema Unificado de Atenção à Sanidade Agropecuária, e dá outras providências. Site Planalto. Disponível em: < http://www.planalto.gov.br/ccivil_03/_ato2004-2006/2006/decreto/d5741.htm>. Acesso em: 15/11/2018.

Instrução Normativa no 13 de $\mathbf{3 0}$ de mar. 2010. Aprova o regulamento técnico para exportação de bovinos, búfalos, ovinos e caprinos vivos, destinados ao abate. Site Ministério da Agricultura, Pecuária e Abastecimento. Disponível em: < http://www.agricultura.gov.br/assuntos/sustentabilidade/bem-estar-

animal/arquivos/arquivos-legislacao/in-13-2010-exportacao-ruminantes-paraabate.pdf>. Acesso em: 15/11/2018.

. Lei no 8.171 de 17 de jan. 1991. Dispõe sobre a política agrícola. Site Planalto. Disponível em: < http://www.planalto.gov.br/ccivil_03/LEIS/L8171.htm>. Acesso em: 11/11/2018.

. Lei no 9.503 de 23 setembro 1997. Institui o Código de Trânsito Brasileiro. Site Planalto. Disponível em: <http://www.planalto.gov.br/ccivil_03/LEIS/L9503.htm>. Acesso em: 15/11/2018.

. Lei no 9.605 de 12 de fev. 1998. Dispõe sobre as sanções penais e administrativas derivadas de condutas e atividades lesivas ao meio ambiente, e dá outras providências. Site Planalto. Disponível em: < http://www.planalto.gov.br/ccivil_03/LEIS/L9605.htm>. Acesso em: 11/10/2018.

Resolução no 675 de 21 jan. 2017. Altera a Resolução CONTRAN № 593, de 24 de maio de 2016, que estabelece as especificações técnicas para a fabricação e a instalação de para choques traseiros nos veículos de fabricação nacional ou importados das categorias N2, N3, O3 e O4. Diário Oficial. Disponível em: < http://www.agricultura.gov.br/assuntos/sustentabilidade/bem-estar-

animal/arquivos/arquivos-

legislacao/DOUde26.06.2017RESOLUON675CONTRANTransportedeanimais.pdf >. Acesso em: 15/11/2018.

CARNEIRO, Luiz Leandro. STF suspende proibição de transporte de animais vivos em Santos. Revista online: Jota.info. 11 out. 2018. Disponível em: $<$ https://www.jota.info/stf/do-supremo/stf-suspende-proibicao-de-transporte-deanimais-vivos-em-santos-11102018>. Acesso em: 10/11/2018.

GRAU, Eros Roberto. A ordem econômica na Constituição de 1988: interpretação e crítica. 3. ed. São Paulo: Malheiros, 1997. 
Personalidade Acadêmica Homenageada:

Augustus B. Cochran III (Agnes Scott College)

MACHADO, Leandro. Exportação de animais vivos para abate dispara e vira alvo de batalhas na Justiça no Brasil. Revista eletrônica: BBC Brasil. São Paulo, 21 fev. 2018. Disponível em: <https://www.bbc.com/portuguese/brasil-43116666>. Acesso em: 10/11/2018.

MACIEL LIMA, Sandra (Org.); SOUZA LIMA, José Edmilson (Org.); MORAIS LIMA, Milena (Org.). A diversidade da pesquisa jurídica: quem disse que o direito não fala com estranhos? 1aㅡ ed. São Paulo: Clássica Editora, 2018.

MEDAUAR, Odete. Direito Administrativo Moderno. 12. ed. rev., atual. e ampl. São Paulo: Revista dos Tribunais. 2008.

MIGALHAS. Ministro Fachin suspende proibição de transporte de animais vivos em Santos. Revista online: migalhas, 26 de abr. 2018. Disponível em: $<$ https://www.migalhas.com.br/Quentes/17,Ml279186,51045-

Ministro+Fachin+suspende+proibicao+de+transporte+de+animais+vivos+em>. Acesso em: 10/11/2018.

MORAES, Alexandre de. Direito Constitucional. 28.ed. São Paulo: Atlas, 2012.

OIE - World Organization for Animal Health. Disponível em: <http://www.oie.int>. Acesso em: 11/11/2018.

SÃO PAULO. Lei Complementar Municipal no 996 de 18 de abr. 2018. Altera e acresce dispositivos da lei $n$ ㅇ 3531, de 16 de abril de 1968, que institui o código de posturas do município de santos, e dá outras providências. Site Prefeitura Santos. Disponível em:

<http://www.santos.sp.gov.br/?q=search/node/lei\%20complementar>. Acesso em: 15/11/2018.

SILVA, João. Livestock and Products Annual. Anuário: USDA Brazil Foreign Agricultutal Service, 9 abr. 2018. Disponível em: <http://www.usdabrazil.org.br/ptbr/reports/livestock-and-products-annual-2018.pdf>. Acesso em: 11/11/2018.

SILVA, José Afonso. Curso de direito constitucional positivo. 19. ed. rev. atual. e ampl. São Paulo: Malheiros, 2001.

SILVESTRE, Gilberto Fachetti; LORENZONI, Isabela Lyrio. A tutela jurídica material e processual da senciencia animal no ordenamento juridico brasileiro: análise da legislacao e de decisões judiciais. Revista Jurídica Unicuritiba, v. 52, n. 3, (2018). Disponível em: <http://revista.unicuritiba.edu.br/index.php/RevJur/article/view/3065/371371599>. Acesso em: 02/06/2019.

SINGER, Peter. Libertação Animal. 1. ed. $2^{a}$ tiragem. São Paulo: Martins Fontes, 2013. 